\title{
REPRESENTAÇÕES DO DESENVOLVIMENTO NAS PÁGINAS DA SÉRIE REALIDADE BRASILEIRA: FASCÍCULOS SOBRE A AMAZÔNIA
}

\author{
Representations of development on the pages of Série \\ Realidade Brasileira: fascicles about Amazon
}

\section{Eduardo de Melo Salgueiro ${ }^{1}$}

\begin{abstract}
RESUMO
Este trabalho tem como objetivo central analisar reportagens de suplementos especiais lançados pela Folha de S. Paulo em 1967 e 1968. Nosso especial interesse reside naquilo que foi escrito a respeito da Amazônia e as representações criadas naquele momento sobre o que deveria ser compreendido como "ideal de desenvolvimento e progresso" para aquela região. Para tanto, utiliza-se o conceito de "representação" desenvolvido por Roger Chartier, pois ele nos ajuda a compreender o modo como, em determinado momento, um grupo pretende hierarquizar, classificar e produzir uma determinada configuração a respeito da realidade. Nesse sentido, operacionalizar esse conceito, aliado à metodologia que é própria dos estudos sobre a imprensa, nos ajuda a compreender melhor o objeto em tela, pois nota-se que, em meio às reportagens aqui analisadas, pretendia-se diagnosticar e elaborar um projeto para a Amazônia. Desse modo, partiu-se da hipótese segundo a qual havia a compreensão de que, para que o discurso desenvolvimentista obtivesse sucesso, era necessário também construir uma série de "representações" do espaço amazônico. Após a análise das fontes, observou-se que as reportagens e artigos efetivamente defendiam uma visão de desenvolvimento e progresso que inaugurou, em certa medida, uma visão que se estendeu abertamente por muito tempo, qual seja, a de que o avanço do capitalismo deve domar e vencer as limitações impostas pela natureza, visão essa que parcialmente se estende até os dias atuais.
\end{abstract}

\footnotetext{
1Professor do quadro efetivo do curso de História do Instituto de Estudos do Trópico Úmido, Campus de Xinguara-PA (Universidade Federal do Sul e Sudeste do Pará). Também atua como como docente do Programa de Pós-Graduação em História (PPGHIST) e do Mestrado Profissional em Ensino de História, ofertados pela mesma instituição. Graduado em História pela Universidade Estadual de Mato Grosso do Sul (UEMS), mestre e doutor em História pela Universidade Federal da Grande Dourados (UFGD). E-mail: eduardomsalgueiro@gmail.com
} 
Palavras-Chave: Imprensa, Amazônia, Desenvolvimento.

\begin{abstract}
This work has as main objective to analyze reports of the special supplements launched by Folha de S. Paulo in 1967 and 1968. Our special interest lies in what was written about the Amazon and the representations created at that time about what should be understood as an "ideal of development and progress" for that region. For this, it is used the concept of "representation" developed by Roger Chartier, as it helps us to understand how, at a given moment, a group intends to hierarchize, classify and produce a certain configuration regarding reality. In this sense, operationalizing this concept, combined with the methodology that is typical of studies about the press, helps us to better understand the object on screen, as it is noted that, in the midst of the reports analyzed here, it was intended to diagnose and develop a project for the Amazon. So, it was started from the hypothesis that there was an understanding that, in order to address the developmentalist discourse to be successful, it was also necessary to build a series of "representations" of the Amazonian space. After analyzing the sources, it was observed that the articles effectively defended a vision of development and progress that inaugurated, to a certain extent, a vision that lasted openly for a long time, that is, that the advance of capitalism must domain and overcome the limitations imposed by nature, a vision that partially remains to the present day.
\end{abstract}

Keywords: Press, Amazon, Development.

\title{
Introdução
}

No curso do século XX até o momento, o espaço conquistado pela imprensa nos estudos históricos cresceu consideravelmente. Entre as várias razões pelas quais os historiadores passaram a recorrer aos impressos periódicos, as diversas representações emitidas por meio de suas páginas certamente colocam esse tipo de fonte como central para a ciência histórica, permitindo um variado leque de possibilidades e enfoques de pesquisa. Nesse sentido, os historiadores e historiadoras brasileiros passaram a fazer uma análise cuidadosa dos periódicos, exercendo uma "leitura dos discursos expressos nos jornais que permite acompanhar o movimento 
das ideias que circulam [em uma] época. A análise do ideário e da prática política dos representantes da imprensa revela a complexidade da luta social" (CAPELATO; PRADO, 1980, p. 94). Pelas palavras publicadas nos periódicos, "se trava uma constante batalha pela conquista de corações e mentes" (CAPELATO, 1988, p. 13). ${ }^{2}$

Dito de outro modo, a partir de clássico texto escrito por Ana Maria Camargo (1971, p. 225), "a imprensa, como meio de expressão das mais diferentes tendências reivindicatórias, apresenta os problemas como foram vistos e sentidos pelos participantes - coloridos, portanto, pela própria vivência da situação". O artigo, escrito pela eminente historiadora brasileira, foi publicado em 1971, isto é, em pleno regime militar. Tal destaque é dado porque o periódico que analisarei insere-se naquele contexto repressivo. $\mathrm{O}$ pano de fundo é a Amazônia do final dos anos 1960.

Esse período ficou lembrado como um momento em que as palavras "desenvolvimento" e "progresso" eram mencionadas correntemente, de tal modo que adentraram o imaginário político-econômico da época, e, provavelmente, ainda hoje, pelo menos entre os historiadores, quando nos remetemos a tal momento histórico, esses termos mencionados estarão entre os mais lembrados. No aspecto político, mesmo se adicionarmos os anos 1950, isto é, no chamado período democrático, que corresponde aos governos de Eurico Gaspar Dutra (1946-1951), Getúlio Vargas (1951-1954), Café Filho (1954-55), Juscelino Kubitschek (1956-1961), Jânio Quadros (1961) e João Goulart (1961-1964), as palavras citadas seguramente foram recorrentes, independentemente de quem estivesse no poder. Isso se estendeu também para o período dos anos 1970, sob o regime militar, que fez uso corrente de um discurso que envolvia crescimento econômico associado ao desenvolvimento e progresso da nação.

A imprensa, naquele contexto, atuou nos debates políticos e nos projetos pensados para a nação. Ainda que o discurso jornalístico dos anos 1950 buscasse uma eventual objetividade e neutralidade, na prática isso não ocorria. É importante lembrar, no entanto, que, a despeito do desenvolvimento da imprensa brasileira em termos de técnicas e avanços tecnológicos na primeira metade do século XX, autores como Carlos Lins da Silva, por exemplo, mantêm ressalvas no que diz respeito à profissionalização do ofício

2 Todas as notas e citações transcritas da bibliografia e das fontes aqui utilizadas, manterão a escrita e pontuação tais como foram registradas em sua época de publicação. 
do jornalismo, sobretudo no que tange à "objetividade" da escrita jornalística. Silva defendia que, por mais que houvesse um incremento tecnológico,

[a] importação de máquinas, a adoção de técnicas, a compra de serviços de agências, a incorporação de valores do jornalismo americano são todos sinais importantes de um desejo de fazer do jornal um negócio. Mas a falta de condições na economia local para sustentar essa vontade faz com que ela se frustre, embora alguns jornais consigam sobreviver [...]. A fragilidade dessa "aventura editorial" até a segunda metade deste século é inquestionável (SILVA, 1990, p. 63).

Nesse sentido, parafraseando Ana Paula G. Ribeiro, mesmo com equipamentos caros e modernos, inclusive a grande imprensa não conseguia manter-se apenas com publicidade e assinaturas, ou seja, era necessário algum outro tipo de apoio, seja por intermédio de verbas oficiais, seja mesmo por meio de grupos privados, para sobreviver financeiramente (RIBEIRO, 2007). Isso significa dizer, claro, que é muito provável que boa parte dos periódicos continuou, de certo modo, presa à prática do jornalismo de opinião, ainda que - e isso é importante - os "posicionamentos políticoideológicos passaram a exigir, no entanto, um pouco mais de sutileza" (RIBEIRO, 2007, p. 247), conforme assevera a autora.

Segundo informam Cardoso de Mello e Novais (a partir da análise de um trabalho empreendido por Bertram Hutchinson), no final dos anos 1950, moradores de São Paulo foram convidados a classificar 30 profissões. Entre elas, o jornalista ocupou a sexta posição nas mais importantes. Segundo os autores, isso se deu justamente porque esse profissional era, "de um lado, considerado um homem público e, de outro, o símbolo de uma relativamente nova e cada vez mais decisiva forma de poder: a imprensa" (CARDOSO DE MELLO; NOVAIS, 1998, p. 588).

Desse modo, partimos da hipótese segundo a qual havia a compreensão de que, para que o discurso desenvolvimentista obtivesse sucesso, era necessário também construir uma série de "representações" do espaço amazônico, isto é, pretendia-se "pintar" um novo retrato desse espaço, considerado ainda no século XX um "inferno verde", a partir de determinados interesses que guiavam a escrita dos artigos publicados no jornal aqui 
apresentado. Dito de outro modo, conforme o conceito é operacionalizado por Chartier (2011, p. 20), era necessário criar "operações de classificação e hierarquização que [produzissem] as configurações múltiplas mediante as quais se percebe[sse] e representa[sse] a realidade". Assim, nosso objetivo será analisar tais representações a partir de suplementos especiais publicados pelo jornal Folha de S.Paulo no ano de 1968.

É importante ressaltar que a Folha já circulava desde 1921, sob o nome Folha da Noite, e sofreu inúmeras transformações até os anos 1960, período no qual foram publicados os suplementos especiais que analisamos no presente texto. Conforme informam Capelato e Mota, a partir de 1962, "o jornal passava à responsabilidade de Octávio Frias de Oliveira e Carlos Caldeira Filho" e, na ocasião em que assumiram a direção do periódico, uma nota da redação foi publicada, ressaltando algo significativo: "A "Folha de S. Paulo' continua a serviço do Brasil, em cujo futuro confia firmemente" (CAPELATO; MOTA, 1981, p. 183, grifos dos autores).

Conforme podemos observar, os diretores acreditavam e firmavam um discurso de que o jornal estava a serviço da nação. É nesse período também que se começa o projeto de reorganização empresarial do complexo editorial do periódico. Ainda na avaliação de Capelato e Mota, a partir de 1962 até 1967, iniciava-se uma "reorganização administrativa e tecnológica", e, entre o período de 1968 a 1974, houve uma "revolução tecnológica" na empresa. O tom mais empresarial dado pelos novos administradores acabou culminando com a recuperação financeira, modernização de suas máquinas e incremento no âmbito da infraestrutura.

$\mathrm{O}$ que nos importa aqui reside no fato de que um projeto mais ambicioso se inaugurava nos anos 1960 e, editorialmente, a Folha de S. Paulo buscava influenciar também os rumos do país. Vejamos, a seguir, como isso se apresentou na Série Realidade Brasileira.

\section{A Amazônia naquele contexto}

Nas décadas de 1960 e 1970, a Amazônia foi palco de grandes projetos empreendidos pelo Estado brasileiro, sendo alguns previamente iniciados na primeira metade do século XX. Os projetos desenvolvimentistas 
pretendiam impulsionar o "progresso" e o "desenvolvimento" daquela região. Conforme ressaltam Cardoso e Müller, foi nesse período que a Amazônia "será, então, zona preferencial para a aplicação de recursos gerados graças à política econômica e fiscal do governo central". Além disso, "interesses estratégicos e militares passaram a motivar mais consistentemente algumas políticas de ocupação da área" (2008, p. 07).

Nesse sentido, foi nessa época que alguns empreendimentos na ordem da infraestrutura ficaram muito conhecidos, como os aeroportos das principais capitais, bem como o avanço das rodovias (destacando-se, aqui, pelo grande apelo midiático à época de sua construção, a BR-230, mais conhecida como rodovia Transamazônica), dos portos e, em especial, a idealização por parte do Estado de "colonizar o vazio" em seus diversos governos (intensificado no regime militar).

A ideia, sem sombras de dúvidas, era elevar aquele "sertão", isto é, "espaço vazio", para a condição de "espaço civilizado", ou dito de outro modo, incorporado ao mundo capitalista e à parte da nação entendida como mais desenvolvida. Pode-se, inclusive, remontar ao famoso preâmbulo escrito por Euclides da Cunha para o livro Inferno Verde, de Alberto Rangel: "Realmente, a Amazônia é a última página, ainda a escrever-se, do Gênesis" (2001, p. 27). Conforme ressalta Nísia Trindade Lima, havia uma ideia de "sertão" historicamente instituída no Brasil, ou seja, aquele espaço no qual havia uma "distância em relação ao poder público e a projetos modernizadores." Assim, "Sertão, nessa perspectiva, é concebido como um dos polos do dualismo que contrapõe o atraso ao moderno, e é analisado com frequência como o espaço dominado pela natureza e pela barbárie" (LIMA, 2013, p. 107).

A Amazônia, por exemplo, na década de 1960, dispunha de um contingente populacional de aproximadamente 2.601.519 habitantes. Passado o período de uma década, verificou-se um considerável acréscimo demográfico, posto que, em 1970, encontravam-se cerca de 4.197.038 habitantes (LOUREIRO; PINTO, 2005, p. 79). Os moradores da Amazônia, em grande parte, provieram de outras localidades para trabalhar nos projetos de infraestrutura na região, bem como tinham em seu horizonte a perspectiva de obter terras e trabalho para sua subsistência. Ademais, o Estado brasileiro, especialmente - mas não exclusivamente - no período militar, buscou mecanismos que incentivassem empresários de outras regiões do Brasil e do exterior a investir capital na Amazônia. 
De acordo com Pereira, a interligação que houve entre a região Norte com o Centro-Sul e o Nordeste brasileiro deu-se por meio rodoviário, "mas também, e, sobretudo, por meio da política econômica e desenvolvimentista do Governo Federal de ocupação dos 'espaços vazios' [que] mobilizou muitos empresários e migrantes pobres rumo à Amazônia em busca de terra, trabalho e de lucro" (PEREIRA, 2013, p. 42). É importante ressaltar, adicionalmente, que essa política de construção da Transamazônica, por exemplo, fazia parte de um conjunto de estratégias do governo que extrapolavam a questão econômica, pois "a decisão de construir esta estrada parece ter sido motivada por duas razões distintas e complementares (...) estratégicas de uma geopolítica preocupada com os "vazios territoriais e demográficos' e o excesso de população pobre no nordeste" (CARDOSO; MÛLLER, 2008, p. 133).

\section{Os Suplementos especiais da Folha de S. Paulo}

É nesse contexto que a Folha de S. Paulo publicou dois suplementos especiais, sendo o primeiro publicado em 16 de abril de 1967, intitulado "Amazônia: o vazio cheio de riquezas", e outro, lançado em vários números, no qual abordou por várias semanas as cinco regiões do país: tratava-se da Série Realidade Brasileira, publicada entre abril e agosto de 1968. O título, por si só, era bastante emblemático, pois trazia em seu nome um impactante "protocolo de leitura", isto é, um sinal visível, ou instrução dirigida claramente ou imposta inconscientemente ao leitor (CHARTIER, 1996, p. 95). Nesse sentido, a Série Realidade Brasileira buscava identificar o que efetivamente era o "Brasil real", mas também pretendia determinar o "Brasil ideal" por meio de suas páginas.

Suas publicações ocorriam da seguinte forma: a cada semana na qual o suplemento era publicado, versava-se sobre determinada região. Assim, em 21 de abril de 1968, inaugurava-se a Série Realidade Brasileira com a produção do fascículo "Brasília: Capital da Integração Nacional", que saiu juntamente com outro, dedicado ao Centro-Oeste, intitulado "Centro-Oeste: vazio em ocupação". 
Além desse fascículo, outros 18 foram lançados até o mês de agosto, incluindo vários suplementos sobre o Nordeste, o Sudeste e o Sul do país, com reportagens que indicavam as potencialidades econômicas dessas regiões. Em relação à Amazônia, houve um destaque maior, a começar pelo que trazia impactante título, muito semelhante ao do Centro-Oeste, qual seja, "A ocupação do vazio: Amazônia". A Figura 1 é sintomática na expressão do tipo de representação que se fazia na época sobre o espaço amazônico.

Das imagens da Figura 1 (logo abaixo), podemos fazer algumas considerações. Inicialmente, observa-se como o suplemento percebia ambos os espaços (Centro-Oeste e Amazônia) ${ }^{3}$ como vazios demográficos, bem como já apresentava — de antemão, em suas respectivas capas as possíveis soluções para enfrentar tal problemática. Ademais, além da percepção acerca da região como um espaço vazio, pretendia-se legitimar o papel do Estado, das elites econômicas do país e determinada compreensão do "desenvolvimento" daqueles espaços, deslegitimando, sem dúvida, outras vivências e sociabilidades já existentes naquelas regiões.

Figura 1 - Série Realidade Brasileira, "Centro-Oeste", de 21 de abril de 1968 (à esq.), e Série Realidade Brasileira, "Amazônia”, de 28 de abril de 1968 (à dir.).

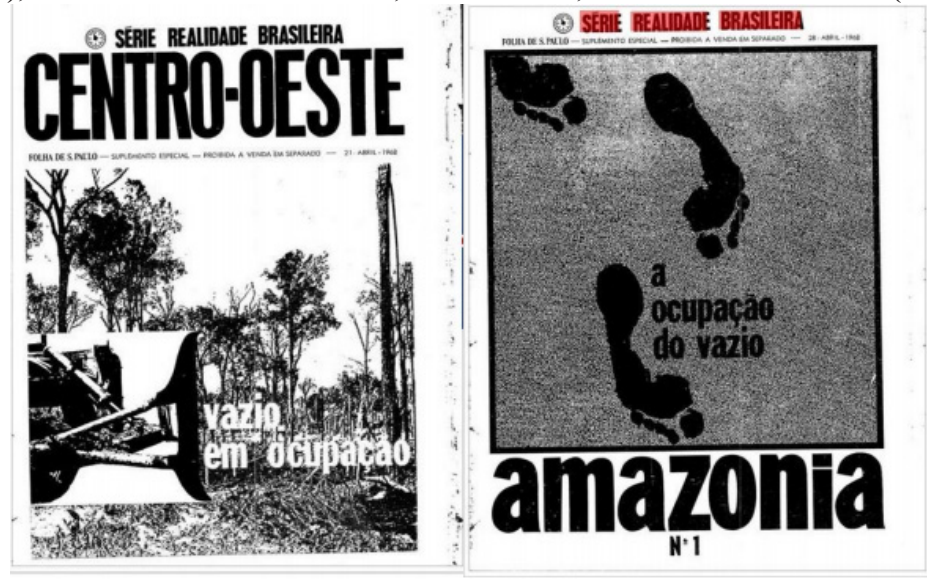

3 É importante lembrar que parte do Mato Grosso estava inserida na chamada Amazônia Legal, que foi criada em 6 de janeiro de 1953 pela Lei no 1.806 (a mesma lei que dispunha sobre a criação da Superintendência do Plano de Valorização Econômica da Amazônia [SPVEA]). 
Como é possível observar, na capa do primeiro suplemento da Folha dedicado à Amazônia, apresentava-se uma imagem de três pegadas humanas que iam em direção à ocupação da região. Naquela correspondente ao Centro-Oeste, a apresentação foi igualmente emblemática, pois a figura ali disposta exibia um trator derrubando a floresta, em uma nítida ideia de civilização em processo de desbravamento da natureza, desafiando-a, de modo que o chamado "homem civilizado" sobrepunha-se à natureza, em um contexto social de poucas preocupações voltadas às questões ambientais. Ao sobrepor-se a ela, o ser humano, legítimo agente provocador dos desequilíbrios ambientais, era convidado, em ambos os suplementos citados, a desbravar, derrubar, ocupar.

No interior do suplemento correspondente à publicação sobre o Centro-Oeste, havia uma legenda que buscava explicar o significado da imagem da capa. Nela, constava a seguinte descrição: "O elemento que compõe o quadro - um trator rompendo a floresta densa e deixando, atrás de si, estradas de penetração - simboliza o processo de ocupação dos grandes espaços vazios do Norte brasileiro, que já começou, irreversivelmente, pelo Centro-Oeste." ${ }^{\prime 4}$

Irreversível, o avanço diante da natureza simbolizava o progresso em um quadro pintado para o futuro. Era o que constava no imaginário dos colaboradores e editores do Suplemento. Isso nos remete ao estudo de Dutra e Silva (2014), que avaliou o caso da rodovia Belém-Brasília em seu período de construção. Para o autor, naquele momento, constituía-se "a tradição de enfrentamento da natureza [que] era evidenciada em nome do progresso" (DUTRA E SILVA, 2014, p. 24).

Ainda nas palavras do autor, eram nítidas as relações existentes "entre as políticas desenvolvimentistas e percepção da natureza como impedimento ao progresso [que, por sua vez,] apresentavam a natureza como inimiga do progresso e que, portanto, a relação estabelecida [na época] incentivava o enfrentamento" (DUTRA E SILVA, 2014, p. 28). Dutra e Silva segue enfatizando que, em meados do século XX, havia um contexto no qual o avanço sobre a natureza inexplorada em nome do progresso era perfeitamente favorável.

4 Série Realidade Brasileira, "Centro-Oeste", de 21 de abril de 1968, [s.p.], grifos nossos. 
Nota-se que a concepção de "espaços vazios" é central naquela narrativa, não só textualmente, mas também pela representação imagética ali disposta, quando se fazia referência ao norte mato-grossense (e, claro, à Amazônia de modo geral). O domínio da natureza media o grau civilizatório do país, encontrando consonância ao ideário norte-americano presente na época (GARFIELD, 2009).

Na Figura 1, por exemplo, nota-se que o espaço amazônico era percebido como "ausente" de "homens". Dito de outro modo, era preciso que se resolvesse a problemática das "terras sem homens para homens sem terra", conforme slogan caro ao governo Médici. Vejamos, mais de perto, o que foi discutido no primeiro fascículo, pois a distribuição de temas merece ser citada, servindo-nos também como protocolo de leitura, no sentido de entendermos os anseios daquele momento. As reportagens e os artigos estão citados no Quadro 1.

Quadro 1 - Títulos das reportagens/artigos do Suplemento Especial - Amazônia, 28 abr. 1968.

\section{Títulos}

A ocupação

Reserva estratégica e econômica

Como investir na Amazônia

Como vive o homem na Amazônia

Pesquisa, prioridade esquecida

O pote de ouro

Uma política de segurança para Amazônia

Abaixo de cada um dos títulos, havia um pequeno resumo do que era abordado no texto. Em relação ao segundo deles ("Reserva estratégica e econômica"), por exemplo, o que foi escrito ia ao encontro do que expomos há pouco em relação ao avanço diante da natureza. Vejamos: “A Amazônia sempre foi considerada como uma reserva, um celeiro em potencial. E é, de fato, uma reserva. Mas não se sabe, com exatidão, o tamanho e o valor dessa reserva. E, até que ponto é lícito manter essa reserva intacta e inexplorada?"5 
Em outro fragmento, abaixo da reportagem "O pote de ouro", também encontramos expressivas considerações, essas ligadas à ideia de segurança nacional:

A falada reserva amazônica é cobiçada, e o foi sempre, por grandes potências mundiais. Um vendedor de terras brasileiras nos EUA já descreveu a Amazônia como um "pote de ouro" que precisa ser "dividido". Fronteiras desguarnecidas e escassa população constituem um perigo para a soberania brasileira na sua Amazônia. ${ }^{6}$

Nas primeiras linhas da reportagem "Reserva estratégica e econômica", uma imagem construída como representação saltava aos olhos, não ficando nada a dever ao discurso do regime militar. Reparemos no peso das palavras transcritas a seguir: "Riqueza sem posse efetiva e espaço sem ocupação diante de um mundo faminto e superpovoado, com algumas potências querendo controlar riquezas e espaços[,] dão uma ideia da dimensão e da importância geo-econômica e geo-política da Amazônia."”

"Riqueza sem posse" e "espaço sem ocupação" estão de acordo com a proposta política do regime militar de "integrar para não entregar" e de colonizar o espaço amazônico. ${ }^{8}$ Todo o primeiro fascículo apresenta a preocupação com a presença externa na Amazônia. Seus textos se iniciam, como mencionado, com um artigo intitulado "Ocupação" e que faz um histórico da região, prosseguindo com outros tantos, que trazem representações e perspectivas futuras para o espaço amazônico.

Ainda sobre o medo de perder aquele espaço, geopoliticamente falando, para o estrangeiro, o resumo das duas reportagens anteriormente mencionadas dava o tom do discurso da Série, de modo geral. Na segunda delas, por exemplo, iniciava-se o texto com uma epígrafe que sintetizava, em boa medida, a mensagem principal e que vale a pena ser citada integralmente:

6 Série Realidade Brasileira, “Amazônia”, O pote de ouro, de 28 de abril de 1968.

7 Série Realidade Brasileira, “Amazônia”, O pote de ouro, de 28 de abril de 1968, p. 34.

8 É importante ressaltar que tais projetos de integração e colonização já se encontram na Marcha para o Oeste, de Getúlio Vargas, bem como no plano de metas de Juscelino Kubitschek. 


\begin{abstract}
"Convite para um encontro ao pé do arco-iris para dividir o pote de ouro" (an invitation to meet at the foot of the rainbow to divide the pot of gold) é o título de um dos folhetos de propaganda de terras brasileiras que o sr. Amos Selling vende nos Estados Unidos. Expressão poética, mas inquietante para os brasileiros e, especialmente, para os escassos habitantes dos $5.507 .490 \mathrm{~km} 2$ da região amazônica, a preferida dos compradores estrangeiros. É uma região de densa floresta equatorial, na qual já foram constatadas imensas riquezas, nos reinos vegetal, mineral e animal. ${ }^{9}$
\end{abstract}

Nesse fragmento, nota-se o temor por parte do editorial em face do discurso de um vendedor de terras estadunidense. Era uma questão que colocava, de certo modo, em xeque "o brasileiro" no âmbito de conquistar a floresta amazônica e ocupá-la. No que diz respeito ao discurso norteamericano, ele consistia na ideia segundo a qual havia um "Eldorado esperando seu conquistador ianque", tal como aponta Garfield (2009) a respeito do contexto da borracha durante a Segunda Guerra Mundial, mas que se repetia nos anos 1960 .

Nas páginas iniciais do primeiro parágrafo de "O pote de ouro", fortes afirmações indicavam a preocupação contida naquelas linhas: "Quando ao desenvolvimento, a Amazônia está defasada mesmo em relação a regiões subdesenvolvidas do Brasil [...]. Uma Amazônia desocupada é o maior entrave para o desenvolvimento e a maior preocupação para os que cuidam da segurança nacional." 10

Nesse artigo, fala-se de todas as potencialidades e da então "imensurável" riqueza que ficava contida na Amazônia. Aqui, a ideia de "Eldorado" faz-se extremamente presente, pois, vencidos a hostilidade da selva e o vazio demográfico, os louros seriam colhidos naquele que era o espaço de maior potencial de riqueza reservada do país. Portanto, o pensamento era o seguinte: "Os brasileiros já sabem que a Amazônia é 'um vazio cheio de riquezas'. O desafio da atual geração é 'a ocupação do vazio'."'11

9 Série Realidade Brasileira, “Amazônia”, O pote de ouro, de 28 de abril de 1968, p. 34.

10 Série Realidade Brasileira, “Amazônia”, O pote de ouro, de 28 de abril de 1968, p. 34.

11 Série Realidade Brasileira, “Amazônia”, O pote de ouro, de 28 de abril de 1968, p. 34. 
O discurso da ocupação do vazio dominava o imaginário brasileiro desde a ditadura Vargas. A necessidade de avançar rumo ao noroeste do país atravessava gerações e chegava às décadas de 1960 e 1970 com muita força, sob a batuta do Estado autoritário, uma vez que este vendia esse discurso de tal modo que um estado como o Pará, por exemplo, apresentava-se como um

[...] território de possível acolhimento para os que não tinham terra, mas também como território que se prestava à elaboração de sonhos, busca de utopias e de realizações. A propaganda governamental, de terra e lucro fácil na Amazônia, somou-se à necessidade [das várias famílias que se deslocaram para aquele espaço] (PEREIRA, 2013, p. 3).

Assim, ainda nas palavras de Pereira:

[...] além da construção de estradas, da criação de órgãos e de programas e do estabelecimento de um sistema de propaganda, prometendo oportunidades econômicas e lucros fáceis na Amazônia, vastas extensões de terras, créditos e incentivos fiscais foram concedidos a grandes empresas e proprietários rurais do Centro-Sul do País para a criação de gado bovino. Dos 1.199 projetos aprovados pela SUDAM, para serem implementados nos anos que transcorreram entre 1975 e 1989, no estado do Pará, por exemplo, 638 eram destinados à criação de gado bovino, 397 à indústria, 68 à agroindústria e 96 aos serviços básicos (telecomunicações, infraestrutura, energia elétrica, transportes etc.) e setoriais (pesca industrial, turismo etc.) (PEREIRA, 2013, p. 6).

Como podemos ver na citação anterior, no período seguinte às publicações da Série Realidade Brasileira, a "febre" da procura por terras baratas trouxe para a região amazônica tanto o trabalhador que buscava sua própria subsistência quanto grandes empreendimentos agropecuários 
ou de outra natureza. ${ }^{12}$ Para os produtores daquele fascículo editorial, o que importava era a ocupação e "efetiva" exploração do "vazio cheio de riquezas". Assim, conclui o texto em um de seus tópicos: "O desafio da atual geração é a ocupação do vazio." 13

No fascículo número 3 (publicado em 12 de maio de 1968), outra simbólica fotografia de capa era apresentada juntamente com um título imponente, como podemos ver na Figura 2.

Figura 2 - Série Realidade Brasileira, “Os caminhos da ocupação: Amazônia", de 12 de maio de 1968.

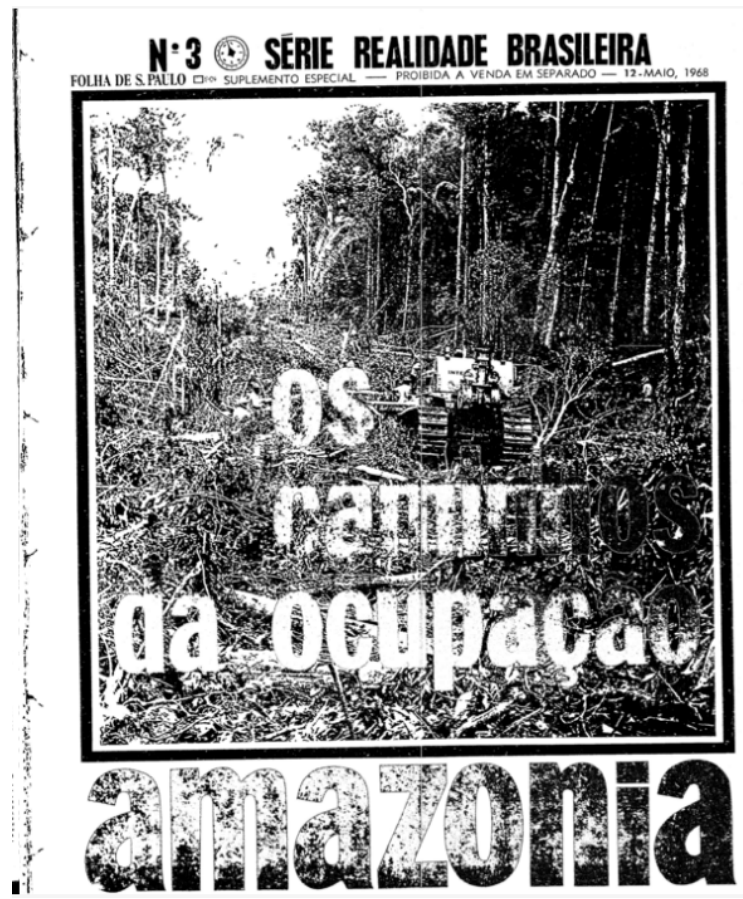

12 Não por acaso, historicamente a região amazônica acolhe dados alarmantes de conflitos de terras, que decorrem do processo mencionado no texto.

13 Série Realidade Brasileira, “Amazônia”, O pote de ouro, de 28 de abril de 1968, p. 34. 
Isso nos remete a outras questões: o que fazer após ocupar o vazio? Quais eram as possibilidades apresentadas pelo periódico em face do contexto da época?

Certamente, intensificar um projeto de infraestrutura regional era uma questão central, pois, conforme ressaltam Loureiro e Pinto,

Durante os anos de 1960 e 1970, os principais obstáculos ao desenvolvimento $[\ldots]$ de regiões atrasadas economicamente como a Amazônia eram atribuídos a dois problemas básicos: à insuficiência de capitais produtivos e de infra-estruturas capazes de pôr em marcha novos investimentos (LOUREIRO; PINTO, 2005, p. 77-78).

Ainda nas palavras dos autores, nessa época entendia-se que "seria possível atrair capitais produtivos, organizados sob a forma de conglomerados econômicos, vindos de outros pontos do Brasil e do exterior, desde que fossem oferecidas vantagens capazes de atrair esses capitais para a região" (LOUREIRO; PINTO, 2005, p. 77-78). Assim, os caminhos da ocupação deveriam ser abertos pela parceria público-privada, o que significa dizer facilidades para investidores alocarem-se na região.

Ao analisarmos um artigo publicado no terceiro fascículo da Série Realidade Brasileira, observa-se interessante avaliação do - à época governador do Amazonas, Danilo Duarte de Mattos Areosa, ${ }^{14}$ em texto publicado sob o título "Uma região a explorar ou a desenvolver?".

Tal texto não é muito extenso, tampouco é profundo. Contudo, traz pelo menos uma concepção de desenvolvimento bastante interessante, e, por essa razão, vale a pena ser mencionada e avaliada aqui. Vejamos, a seguir, qual era a ideia central do autor:

Não é esta, a Amazonia, como a entendo e como a sinto, como a conheço; não é esta, a Amazonia uma região a explorar, se considerarmos a exata significação que o vocábulo deve ter,

14 Danilo Duarte de Mattos Areosa foi governador do Amazonas entre 1967-1971 pelo partido Arena, indicado pelo então chefe do regime autoritário Humberto de Alencar Castelo Branco. 
aqui e na oportunidade. É, sim, uma região a desenvolver, uma região a preparar, a fim de que nela, nas suas aguas, nas suas florestas, no seu solo e embaixo dele, se processe, em extensão e profundidade, uma seria e objetiva, equilibrada e sensata também, arrancada de desenvolvimento. A fase mais importante da preparação será construir um complexo de infra-estrutura que permita ao homem, mais facilmente, menos asperamente, aproveitar e tornar uteis os bens que a Natureza pode oferecer. ${ }^{15}$

Para o governador Areosa, o tempo de "explorar" a Amazônia já havia passado. Ainda que não fique explícito, tudo leva a crer que o autor fazia referência ao período no qual viajantes e naturalistas catalogavam a flora e a fauna da região amazônica. Havia chegado o momento em que "desenvolver" significava verdadeiramente aproveitar os recursos naturais, bem como criar uma infraestrutura adequada aos objetivos desenvolvimentistas da época. É válido dizer que foi em seu governo que se inaugurou a Zona Franca de Manaus, e, em seu projeto de governo, era absolutamente necessário "aproveitar" os bens que a natureza oferecia.

Tal visão remete-nos a uma propaganda veiculada na revista Veja, em dezembro de 1970, e que foi analisada pela historiadora Edilza Fontes. Nela, há um mapa do Brasil em branco, exceto na parte correspondente à Amazônia, que, por sua vez, apresenta uma série de representações que fazem alusão ao desenvolvimentismo da época, tal como um boi, que corresponde a projetos agropecuários financiados pela Sudam, ou empreendimentos relacionados com a Zona Franca de Manaus.

O fato é que, na parte branca do mapa, há a seguinte mensagem: "Chega de lendas, vamos faturar!”. Conforme indica Fontes, a representação "é uma proposta de futuro para a região, assinada por órgãos federais do governo brasileiro. $\mathrm{O}$ anúncio é assinado pelo banco da Amazônia e pelo ministério do interior", isto é, trata-se de uma mensagem na qual o "Estado [está] dizendo qual o futuro que ele pretende incentivar, possibilitar na região". Para concluir, escreve a autora:

15 Série Realidade Brasileira, "Os caminhos da ocupação: Amazonia”, Uma região a explorar ou a desenvolver?, de 12 de maio de 1968, p. 117, grifos nossos. 
Chega de lendas, vamos faturar indica que o passado da floresta serviu para abrigar lendas e não desenvolveu a região. É chegada [a] hora de mudar a forma de ocupação do solo e dos usos da floresta. É necessário incluir a região ao resto do país. A floresta é um espaço para faturar, para enricar. É um chamado para se tirar proveito das riquezas da Amazônia. Expressa uma política de incentivos fiscais para [a] região. O estado estaria oferecendo incentivos para quem quisesse investir na região. A região é um empreendimento. Um espaço vazio. Uma fronteira aberta. Uma fronteira para implantação de relações capitalistas de produção (FONTES, 2017, p. 166).

Nota-se que a representação publicada na revista Veja por meio de uma propaganda estatal expressava uma tentativa de classificação de um futuro ideal para a região. Se retomarmos o texto do governador Areosa, observaremos que ele entende "desenvolver" não mais como "catalogar" (explorar), mas como avançar sobre a natureza. Em suas palavras, "de origem intensamente selvagem, embora, domada a região já foi; a etapa futura, e que urge realizar a partir de agora, é a de domesticá-la. E esta etapa é o nosso dever e o nosso compromisso, da geração presente do Brasil e das que nos sucederem". ${ }^{16}$ Segundo Becker (2001, p. 135), esse modelo de economia compreende que "o progresso é entendido como crescimento econômico e prosperidade infinitos, baseados na exploração de recursos naturais percebidos como igualmente infinitos".

Decorre disso enorme preocupação em defender aquela região como um espaço nacional. No decurso do regime militar, a preocupação com a proteção das fronteiras e a ocupação por meio de uma estratégia "racional" foi central em termos de políticas públicas governamentais. Domesticar a natureza exigia, por certo, sua ocupação. Preencher o vazio significava proteger e desenvolver.

Em outro suplemento especial, que antecedeu àqueles de 1968, a Folha de S. Paulo lançou, em 1967, a seguinte publicação: "Amazônia: um vazio cheio de riquezas".

16 Série Realidade Brasileira, "Os caminhos da ocupação: Amazonia", Uma região a explorar ou a desenvolver?, de 12 de maio de 1968, p. 117, grifos nossos. 
Ao virar a primeira página daquele caderno especial, o leitor se depara com uma propaganda de uma bebida alcóolica que dizia em letras grandes, "um brinde ao progresso da Amazônia com cerveja da Amazônia".17 A "entrada" mostra-se bastante convidativa, pois, na página seguinte, o editorial é escrito pelo diretor da Sucursal Norte/Nordeste Calazans Fernandes, intitulado emblematicamente "Vazio". Percebe-se que há uma consonância entre aquilo que se apresenta no anúncio e o que se pretende naquela publicação. Conforme ressalta Barzotto, embora falando de outra modalidade de publicação, esse é o caso no qual fica nítido que o anunciante e aquilo que ele anuncia não se apresentam somente como "publicidade, mas [indicam] uma concepção de sociedade, tanto através de peças publicitárias como também através das matérias publicadas" (BARZOTTO, 1992, p. 12).

Figura 3 - Suplemento Especial da Folha de S.Paulo, "Amazônia: um vazio cheio de riquezas", de 16 de abril de 1967.

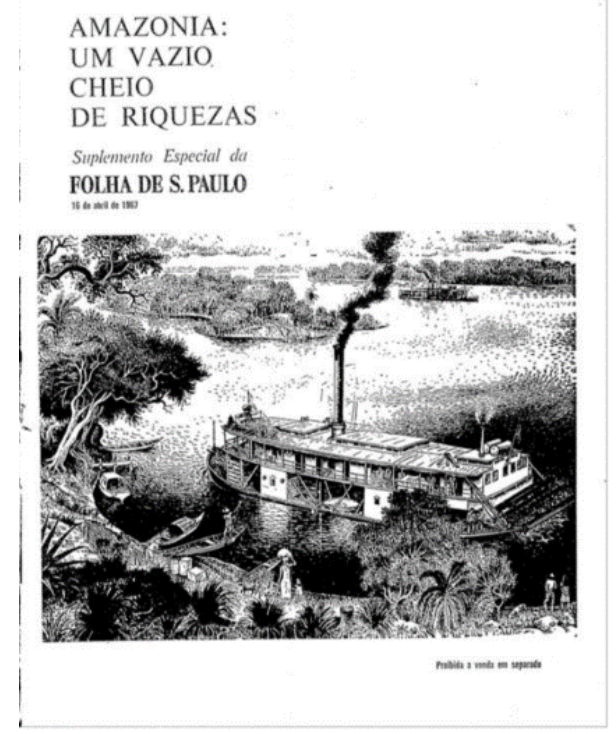

17 Suplemento Especial da Folha de S.Paulo, “Amazônia: o vazio cheio de riquezas”, de 16 de abril de 1967. 
A representação da capa simbolizava (Figura 3) o que aquele editorial desenhava para a época, isto é, um espaço no qual o vagaroso ritmo fluvial precisava ser superado. Foram várias as frases de efeito naquele texto, nas quais várias representações podem ser vislumbradas. Vejamos, a seguir:

A história da Amazonia tem sido cultivada e mesmo defendida com o sangue de brasileiros, mas até hoje não se conseguiu escrevê-la. Pois a Amazonia permanece, na quase totalidade de sua extensão, indevassada e impenetrada pelo homem. ${ }^{18}$

Mais adiante, Fernandes escreve sobre a ineficaz apropriação por parte dos homens daquela imensidão toda. Em sua leitura, o melhor da ocupação ainda estava por vir, conforme podemos visualizar nas palavras do autor:

No passado, o povoamento da Amazonia foi feito por brasileiros, por nordestinos $[\ldots]$ que, juntamente com os "caboclos" [...] e europeus - garantiram e ampliaram a penetração brasileira na região.

Mas essa penetração não se fez em bases efetivas e suficientes para garantir uma ocupação proporcional ao imenso espaço físico da Amazonia. Representando quase $2 / 3$ do territorio nacional, a Amazonia tem o baixo índice de menos de um habitante por $\mathrm{km} 2$. Dentro de um mundo com áreas superpovoadas ameaçadas pela explosão social e onde $2 / 3$ dos povos vivem a fome crônica, a posse da Amazonia chega a ser reclamada como medida de solidariedade universal. ${ }^{19}$

Nota-se que a preocupação maior era a de habitar/ocupar aquela região "vazia". Seu vazio, claro, não era apenas demográfico, mas um "vazio

18 Suplemento Especial da Folha de S.Paulo, "Amazônia: o vazio cheio de riquezas", de 16 de abril de 1967, p. 3 .

19 Suplemento Especial da Folha de S.Paulo, "Amazônia: o vazio cheio de riquezas", de 16 de abril de 1967, p. 3 . 
de progresso", isto é, a ausência de projetos que pudessem elevar aquele lugar ao status de região desenvolvida. Conforme ressalta até o anúncio da cerveja há pouco mencionado, faltava o progresso a ser brindado. Sob esse aspecto, diz o editorial que

[...] busca o Suplemento mostrar o grande campo aberto à iniciativa privada na Amazonia e o desafio que se coloca para a imaginação criadora do empresariado nacional, indicando, nesse sentido, as portas de entrada da ocupação amazonica, as oportunidades para investimentos industriais e a legislação especial de incentivo à livre empresa. ${ }^{20}$

Ao final do texto, uma apoteótica conclusão:

Na extensa linha de 12 mil $\mathrm{km}$ de limites da Amazonia brasileira com sete nações sul-americanas, os índios no seu estado mais primitivo, as desguarnecidas unidades militares e as seringueiras distribuídas em dispersos aglomerados humanos constituem a fronteira viva do Brasil. ${ }^{21}$

De todo modo, o fato é que o editorial antecede uma série de publicações que visava a apresentar outra perspectiva da Amazônia, qual seja, aquela que vislumbrava alcançar o status de região desenvolvida sob o impulso do progresso que urgia na época.

É válido ressaltar que o caderno especial de 16 de abril de 1967 foi parecido em sua proposta com os que vieram subsequentemente (na Série Realidade Brasileira), mas, ao mesmo tempo, diferenciou-se por sua extensão, isto é, foram expressivas 184 páginas, divididas em 51 textos

20 Suplemento Especial da Folha de S.Paulo, “Amazônia: o vazio cheio de riquezas”, de 16 de abril de 1967, p. 3.

21 Suplemento Especial da Folha de S.Paulo, "Amazônia: o vazio cheio de riquezas", de 16 de abril de 1967, p. 3. 
dedicados apenas à Amazônia. Em seu sumário, pode-se observar uma miríade de temas.

Um dado interessante a ser observado em todas as publicações aqui analisadas assenta-se no fato de que, ao lado do sumário/índice, há sempre uma indicação da bibliografia utilizada para fundamentar os textos ali dispostos. Isso indica que havia uma grande preocupação em apresentar dados e informações baseados em estudos técnicos, de modo que isso tornasse os textos ali veiculados mais fidedignos e autorizados a falar sobre a Amazônia.

Muitos textos dedicavam-se a escrever sobre os projetos de desenvolvimento oriundos de políticas públicas para a Amazônia. No primeiro deles (sem assinatura), que abria a série de reportagens, logo após o editorial, algumas considerações feitas pelo autor merecem ser destacadas. O título era "Auto desenvolvimento à Amazonia". Se não temos a informação sobre seu autor, ao menos o lugar de onde o texto foi escrito é apresentado. De Recife $(\mathrm{PE})$, as palavras iniciais faziam referência à recém-criada Superintendência de Desenvolvimento da Amazônia (Sudam), fundada para "alterar a estrutura da economia amazônica, de forma a que os setores industrial e agrícola passem a ter preponderância sobre os setores comercial e extrativo, de modo a criar condições dinâmicas para o autodesenvolvimento". ${ }^{22}$

A discussão, mais especificamente, relacionava-se com o primeiro plano quinquenal da Sudam, que buscava atingir sete objetivos principais. Conforme ressalta Becker (2001, p. 137), esse foi o momento no qual o "Estado tomou a si a iniciativa de um novo e ordenado ciclo de devassamento amazônico, num projeto geopolítico para a modernidade acelerada da sociedade e do território nacionais". Conforme indica o texto publicado no caderno da Folha:

[...] o Plano Quinquenal pretende alcançar mais sete objetivos gerais e prevê, para isso, investimentos globais de NCR\$ 2.939.000.000 [...], 41,8\% desses recursos (ou seja, NCR\$ 1.249.000.000 — Um bilhão, duzentos e quarenta e nove milhões de cruzeiros novos) correspondem às necessidades de

22 Suplemento Especial da Folha de S.Paulo, "Amazônia: o vazio cheio de riquezas", de 16 de abril de 1967, p. 6. 
recursos externos — de fora da Amazônia — principalmente para investimentos chamados "autônomos", cujo suprimento caberá, fundamentalmente ao poder público. Os restantes $52,2 \%$ devem ser preenchidos com "investimentos induzidos", a cargo especialmente da iniciativa privada. ${ }^{23}$

Essas informações trazem números relacionados com os investimentos previstos no Plano. Contudo, o que nos importa para o caso em tela é aquilo que diz respeito aos $52,2 \%$ mencionados, que deveriam ser investidos pela iniciativa privada. $\mathrm{O}$ que nos parece importante destacar não é nem mesmo a conhecida participação da iniciativa privada em todo o processo que corresponde ao plano regional para a Amazônia, mas os anúncios veiculados ao longo daquele artigo. Um deles era do "Banco Brasileiro de Descontos S.A. (Bradesco)", e o outro, da "Cia. Sul-Americana de Investimentos, Crédito e Financiamento". Ambos ocupavam uma página inteira, situados do lado direito do suporte daquela publicação, lugar destinado sempre aos grandes anunciantes, por serem mais caros. Conforme ressalta Luzmara Ferreira,

[...] a página da direita é privilegiada por seu aspecto físico, dada a maior mobilidade das páginas à esquerda do suporte, a direita, é a página na qual o leitor detém mais o olhar, por ser aquela que primeiro desvela-se ao olhar [do] leitor, ao virar de páginas, além de apresentar-se sem as ondulações características da página esquerda, que graças ao modo como as folhas são coladas impede que as mesmas se apresentem planas. Por se tratar de um lugar privilegiado da revista, a página da direita tornou-se um produto comercialmente mais caro (FERREIRA, 2003, p. 113).

Ao folhearmos o caderno especial, bem como os outros quatro publicados na Série Realidade Brasileira, observaremos grandes anunciantes relacionados com o mundo das finanças. É certo, no entanto, que tal

23 Suplemento Especial da Folha de S.Paulo, "Amazônia: o vazio cheio de riquezas", de 16 de abril de 1967 , p. 6. 
abordagem merece um trabalho especialmente dedicado a isso, e não é nosso intento fazê-lo no presente texto. Por essa razão, voltamos ao tema principal em análise.

$\mathrm{O}$ autor dividiu seu texto em vários tópicos, destinados a abordar uma problemática e que tinham como eixo central as questões a seguir:

I - NAAREA GEOGRAFICA

A. Extensão física e dispersão dos núcleos populacionais existentes;

B. Desconhecimento do potencial efetivo de recursos naturais.

II - NAAREA SOCIAL

A. Escassez de recursos humanos para a ocupação das fronteiras econômicas e geográficas;

B. Necessidade de concentração demográfica, para eficiente assistência educacional e sanitária.

III - NA AREA ECONOMICA

A. Dualismo econômico (baixa produtividade na zona rural e grande concentração das atividades na zona urbana) decorrente da base extrativista original da economia amazônica;

B. Precariedade da infra-estrutura econômica para atender às necessidades de transporte, comunicações e energia dos núcleos populacionais.

C. Precariedade do abastecimento de produtos populacionais e dificuldade de saneamento das safras;

D. Industrialização incipiente com a preponderância de pequenas industrias sem artesanais ao lado de enclaves de grande porte.

IV - NA AREA INSTITUCIONAL

A. Insuficiência de espirito empresarial e falta de estimulo à iniciativa privada;

B. Integração nacional inadequada a falta de coordenação na atuação dos órgãos públicos locais. ${ }^{24}$

Nota-se que um dos aspectos que mais preocupavam era aquele que dizia respeito à população, isto é, a baixa concentração demográfica.

24 Suplemento Especial da Folha de S.Paulo, "Amazônia: o vazio cheio de riquezas”, de 16 de abril de 1967, p. 6 , grifos nossos. 
Como temos mostrado no decorrer deste trabalho, as questões relacionadas à "dispersão dos núcleos populacionais" e à "escassez de recursos humanos" eram centrais nas matérias que encontramos nos cadernos especiais aqui analisados.

Assim segue o texto, e encontramos no tópico intitulado "Colonização" importantes considerações sobre o tema. O autor afirmava que: "Numa região despovoada (a média é de um habitante por quilometro quadrado), a colonização, como processo de ocupação e produção, tem de ser parte importante em qualquer programa de desenvolvimento." ${ }^{25}$

Antes desse fragmento, no entanto, trazia elemento importante em seu discurso, ao mostrar preocupação com a colonização e o aproveitamento do espaço, que era visto em seu pior aspecto no então já ultrapassado extrativismo, segundo sua concepção. Em suas palavras, a colonização devia seguir um plano racional, de modo que pudesse superar as contradições existentes naquele período. São aspectos otimistas e pessimistas apresentados na citação a seguir:

A Amazônia tem, como característica mais evidente a sua extensão territorial e a sua rarefação demografica. Numa área correspondente a $42 \%$ do Brasil vivem apenas 3,7\% de sua população. No diagnóstico que faz sobre a economia amazônica, o Plano Quinquenal salienta, no entanto, que esses dados médios não descrevem, com exatidão a situação real, porque "existem areas de grande econcentração populacional e outras praticamente desabilitadas". E reforça a colocação com a informação de que a população urbana já deve representar cerca de $40 \%$ da população total.

O subdesenvolvimento da Amazonia configura-se, em sua expressão mais primitiva, nas áreas dedicadas ao extrativismo e sujeitas ao regime de coleta comercial. Desde 1950, no entanto, que a participação do extrativismo produto bruto da região baixou substancialmente: de $20,6 \%$ em 1953 , para $11,3 \%$ em $1962 .^{26}$

25 Suplemento Especial da Folha de S.Paulo, “Amazônia: o vazio cheio de riquezas", de 16 de abril de 1967, p. 12.

26 Suplemento Especial da Folha de S.Paulo, “Amazônia: o vazio cheio de riquezas”, de 16 de abril de 1967, p. 6. 
Nota-se que havia forte preocupação com a ocupação, ainda que, em alguma medida, relativizada. Já no segundo momento do fragmento acima, fica bastante evidente que o extrativismo deixava, aos poucos, de ser o motor do desenvolvimento econômico da Amazônia, atrapalhando - inclusive a questão do desenvolvimento demográfico.

Quando se falava em colonização, o texto apresentava uma visão interessante, relacionando-a diretamente com o ainda embrionário desenvolvimento da agropecuária, que, futuramente - como se sabe -, assumiria enorme destaque na economia amazônica, bem como nos problemas sociais da região. Vejamos como se apresentava tal questão:

\section{COLONIZAÇÃO}

Apenas $11,5 \%$ da superfície da região é ocupada por estabelecimentos agropecuários, $84 \%$ dos quais são estabelecimentos com área inferior a 100 hectares, embora representando, apenas, $5 \%$ da área de estabelecimentos. Os estabelecimentos superiores a 10.000 hectares, embora sejam somente 0,12 em número, representam $54 \%$ da área de todos os estabelecimentos.

As colônias existentes na Amazônia têm sido implantadas sem estudos básicos e com poucos recursos [...].

Entre os fatores responsáveis pelos frequentes insucessos nas tentativas de colonização, na Amazônia, podem citar-se ainda: a) a localização inadequada; b) conflito entre colonos por falta de legalização da posse da terra; c) baixa produtividade, devido a carência técnica, pragas e deficiência de comercialização; d) desamparo jurídico e social dos colonos.

Devido a isso, o aproveitamento dos fluxos migratórios para a Amazônia tem sido deficiente, devendo atribuir-se ao desentrosamento entre os diversos órgãos colonizadores que operam na região grande parte dos problemas existentes. ${ }^{27}$

O texto apresenta fatores controversos relacionados com a colonização, incluindo a problemática disputa de terras em virtude de

27 Suplemento Especial da Folha de S.Paulo, "Amazônia: o vazio cheio de riquezas", de 16 de abril de 1967, p. 12. 
complicações relativas à legalização e à localização das posses ${ }^{28}$ ao latifúndio, à carência na produção em virtude de problemas técnicos, bem como aos problemas sociais envolvendo os colonos.

Ainda é importante destacar que a agropecuária se apresentava como uma das saídas para a baixa produtividade do extrativismo e como um chamarisco para futuros colonos que, porventura, tivessem interesse em ocupar aquelas terras.

O último texto a ser analisado foi intitulado "Como eu vi a Amazônia". Escrito pelo ex-ministro da Coordenação dos Organismos Regionais, João Gonçalves de Souza, algumas de suas visões mostram-se interessantes. Suas palavras iniciais dão o tom do discurso, como podemos observar a seguir: "Quem fecha os olhos e com a imaginação procura abarcar o espaço amazônico e suas fronteiras tem a impressão de um enorme leque aberto, sustentado por mão cujo punho é o estuário do rio Amazonas." ${ }^{29}$

A Amazônia, em sua forma de leque, dizia o autor, trazia um problema de conteúdo, isto é, "o vazio humano e econômico que de fato a região revela". Mais uma vez, como podemos observar, a ideia de espaço desocupado assentava-se tanto no que dizia respeito à baixa densidade demográfica quanto em sua economia. Isso nos remete à citação do texto " $\mathrm{O}$ vazio cheio de riquezas", localizada na nota de rodapé número 27 , na qual é dito que, para além da exímia população, havia - por consequência ou problema "de origem" — "insuficiência de espírito empresarial".

O vazio é central em todos os textos aqui apresentados e ele ultrapassa a questão demográfica. É como se toda a Amazônia Legal não tivesse história. Era preciso construí-la a partir daquela conjuntura. Não é demais mencionar que, segundo Leal (1988), citado por Marques e Trindade (2014, p. 171), "a arrancada da ocupação produtiva na Amazônia passou a se dar efetivamente a partir de 1967, quando se tem a conjunção de medidas e ações institucionais no sentido de promover a ocupação da região".

No artigo escrito por João Gonçalves de Souza, várias representações da Amazônia faziam-se presentes, e, na medida que os parágrafos avançam, tem-se a percepção de que há uma repetição notável de certa visão de mundo que perpassa não somente esse caderno especial, mas também toda a Série Realidade Brasileira.

28 Esse tema foi muito debatido em Pereira (2013).

29 Suplemento Especial da Folha de S.Paulo, "Como eu vi a Amazônia”, de 16 de abril de 1967, p. 24. 
Oautorressalta quais eramos maiores empecilhos ao desenvolvimento da Amazônia, remetendo-nos a textos já analisados anteriormente. Em suas palavras, havia o vazio demográfico: “Com um patrimônio extraordinário de reservas naturais praticamente intocadas, na Amazônia vive um brasileiro perdido em quase dois quilômetros quadrados." O tom de ironia deixa ainda mais explícito seu intuito, isto é, trazer à luz o grande problema amazônico: a baixa demografia.

Mais adiante, apresenta quatro aspectos, considerados por ele de primeira importância, quando se falava em desenvolver a Amazônia:

Para mim o problema da Amazônia apresenta quatro aspectos distintos, mas interdependentes, a saber: a) povoamento e ocupação humana; b) criação de uma economia interna, autosustentável; c) vivificação das faixas de fronteira; d) integração da Amazônia no resto do país e no Continente. ${ }^{30}$

Feito o diagnóstico, Gonçalves de Souza faz as seguintes observações:

Quanto ao desafio do povoamento, assinalo, já não poderia o Brasil continuar desmuniciado de uma política e de um plano capazes de povoar o deserto verde.

$[\ldots]$

A ausencia de população na Amazônia seria assim automaticamente contrabalançada pelos excessos demográficos das outras regiões.

De outro lado, toda a estrutura da economia amazonica é baseada em atividades extrativas. O tempo atual já não mais o justifica.

A Amazônia necessita reforçar seus atuais e rarefeitos polos de desenvolvimento economico. Precisa ligá-los entre si. Pode diversificar a sua economia, tendo em vista mercados internos e externos. [...]

As fronteiras na região constituem problema sério para o país, até de segurança para o futuro. Esta fronteira abrange $7.300 \mathrm{~km}$

30 Suplemento Especial da Folha de S.Paulo, "Como eu vi a Amazônia", de 16 de abril de 1967, p. 24. 
de extensão, $[\ldots]$

Por fim, há um problema de integração da região no resto do país. É tema de mais alta importância. ${ }^{31}$

Observa-se que o autor ainda visualiza a Amazônia como um "deserto verde", ausente tanto de pessoas quanto de projetos de desenvolvimento. Apresenta como uma possível solução o balanceamento demográfico entre as regiões do país, trazendo contingente populacional de outros espaços - como o Nordeste, por exemplo - para a fronteira amazônica, a fim de ocupar aquele "vazio".

No que tange à questão do desenvolvimento econômico, reforça a ideia segundo a qual era preciso criar polos interligados e diversificados no âmbito da economia, especialmente porque, para ele, assim como em outro texto já apresentado, a estrutura extrativista já não poderia mais ser aceita e justificada. Era preciso diversificar.

Ademais, chamava-se a iniciativa do Estado para inverter aquele cenário, modificar aquela paisagem e "pintar" com as cores do desenvolvimento aquela tela verde, que ansiava pelo cinza do concreto e o preto do asfalto.

\section{Considerações Finais}

Em todas as edições dos suplementos especiais da Folha de S.Paulo aqui analisadas, observamos visões e representações de um espaço que deveria ser obrigatoriamente ocupado demograficamente, mais especialmente ainda (ocupado), pelo Estado e por empresas nacionais e estrangeiras, de modo que fossem ali instalados projetos capitalistas que pudessem fazer um uso "racional" das "imensuráveis riquezas" da Amazônia.

Nas décadas que se seguiram, inúmeras contradições emergiram de tais projetos e ações governamentais ou privadas no interior da Amazônia

31 Suplemento Especial da Folha de S.Paulo, "Como eu vi a Amazônia”, de 16 de abril de 1967, p. 24. 
Legal. Conforme indica Jean Hébette, no curso dos anos 1960, iniciaram-se os grandes projetos de desenvolvimento para a região e, mais importante que isso, "na aparência de um aceno amigo [o que observamos foi] um abraço traiçoeiro, pois adjacente à "promessa de dias melhores e de juramentos de prosperidade futura" emergiu a "ameaça da destruição ambiental, da desintegração social e cultural” (HÉBETTE, 1991, p. 7).

Nesse sentido, o que observamos foi que ao ser lançado um olhar sobre as propagandas, reportagens e aos artigos que circularam nos suplementos da Folha de S. Paulo, notou-se que suas páginas foram abertas para o discurso do desenvolvimento e progresso a todo custo. Representações foram construídas por meio daquelas páginas, tais como a Amazônia como um "deserto verde", "lugar inóspito" e "subdesenvolvido". Desde então, decorreram diversas práticas, que foram efetivadas no curso dos anos até os dias atuais, pois o que nos parece central foi a construção de uma visão de mundo que alimentou a ideia segundo a qual para a região amazônica só restaria o avanço sobre a floresta e o uso dos seus recursos naturais, por meio de projetos de todo tipo, destacando-se, por exemplo, aqueles relacionados aos setores agropecuário, energético e minerador.

\section{Referências}

BARZOTTO, Valdir. Leitura de propaganda de agrotóxicos: contribuição aos estudos da ideologia da modernização. 1992. 107f. Dissertação (Mestrado em Linguística), Unicamp, Campinas, 1992.

BECKER, B. K. Revisão das políticas de ocupação amazônica: é possível identificar modelos para projetar cenários? Parcerias Estratégicas, Brasília, v. 12, p. 135-159, 2001.

CAMARGO, Ana Maria de Almeida. A imprensa periódica como fonte para a história do Brasil. In: DE PAULA, Eurípides Simões (Org.). In: V SIMPÓSIONACIONALDOSPROFESSORESUNIVERSITÁRIOS DE HISTÓRIA. Anais... São Paulo, 1971. v. II, p. 225-239.

CAPELATO, Maria Helena. Imprensa e história do Brasil. São Paulo: Contexto/Edusp, 1988. 
CAPELATO, Maria Helena; MOTA, Carlos Guilherme. História da Folha de S. Paulo (1921-1981). São Paulo: Impress, 1981.

; PRADO, Maria Ligia. O bravo matutino: imprensa e ideologia no jornal O Estado de S. Paulo. São Paulo: Alfa-Ômega, 1980.

CARDOSO, Fernando Henrique; MÜLLER, Geraldo. Amazônia: expansão do capitalismo. Rio de Janeiro: Centro Edelstein de Pesquisas Sociais, 2008.

CARDOSO DE MELLO, José M.; NOVAIS, Fernando. Capitalismo tardio e sociabilidade moderna. In: SCHWARCZ, Lilia M. História da vida privada do Brasil: contrastes da intimidade contemporânea. São Paulo: Companhia das Letras, 1998.

CHARTIER, Roger. Defesa e ilustração da noção de representação. Fronteiras, Dourados, MS, v. 13, n. 24, p. 15-29, jul./dez. 2011.

$$
\text { . Do livro à leitura. In: }
$$

(Org.). Práticas de

leitura. São Paulo: Estação Liberdade, 1996.

CUNHA, Euclides da. Preâmbulo. In: RANGEL, Alberto. Inferno verde. Manaus: Editora Valer, Governo do Amazonas, 2001.

DUTRA E SILVA, Sandro. O desbravador do Oeste e as narrativas do enfrentamento e devastação da natureza na construção da rodovia Belém-Brasília. Fronteiras: Revista Catarinense de História [online], Florianópolis, n. 23, p. 21-36, 2014.

FERREIRA, Luzmara C. Prática de leitura: os limites instaurados pela materialidade do suporte de textos revista. 2003. 158f. Dissertação (Mestrado em Letras) - Programa de Pós-Graduação em Letras, Unesp, Araraquara, 2003.

FONTES, Edilza J. O. Paisagens amazônicas: o espaço vazio e a floresta. In: COELHO, Anna Carolina de Abreu; ALVES, Davison Hugo Rocha; NEVES NETO, Raimundo Moreira das (Org.). Perspectivas de pesquisa em história da Amazônia: natureza, diversidade, ensino e direitos humanos. 1. ed. Belém: Açaí, 2017. v. 1, p. 147-171.

GARFIELD, Seth. A Amazônia no imaginário norte-americano em tempo de guerra Revista Brasileira de História. São Paulo, v. 29, no 57, p. 19-65 -2009 . 
HÉBETTE, Jean (Org.). O Cerco está se fechando. O impacto do grande capital na Amazônia. Belém: NAEA/UFPA, 1991.

LEAL, Aluizio Lins. Uma sinopse histórica da Amazônia (uma visão política). In: TRINDADE, J. R. B.; MARQUES, G. (Orgs.). Revista de Estudos Paraenses (edição especial). Belém: IDESP, 2010.

LIMA, Nísia Trindade. Um sertão chamado Brasil/ Nísia Trindade Lima. São Paulo: Hucitec, 2013.

LOUREIRO, Violeta Refkalefsky; PINTO, Jax Nildo Aragão. A questão fundiária na Amazônia. Estudos Avançados, São Paulo, v. 19, n. 54, maio/ago. 2005.

MARQUES, G. de S.; TRINDADE, J. R. B. Para além da SPVEA: elementos para a interpretação da intervenção estatal na Amazônia. In: TRINDADE, José Raimundo Barreto (Org.). Seis décadas de intervenção estatal na Amazônia: a SPVEA enquanto auge e crise do ciclo ideológico do desenvolvimentismo brasileiro. 1. ed. Belém: Paka-Tatu, 2014. v. 1, p. 153-183.

PEREIRA, Airton dos Reis. A luta pela terra no sul e sudeste do Pará: migrações, conflitos e violência no campo. 2013. 278f. Tese (Doutorado em História) - CFCH, Universidade Federal de Pernambuco, Recife, 2013.

RIBEIRO, Ana Paula G. Imprensa e história no Rio de Janeiro dos anos 1950. Rio de Janeiro: e-papers, 2007.

SILVA, Carlos Lins da, $O$ adiantado da hora: a influência americana sobre o jornalismo brasileiro. São Paulo-SP, Summus Editorial, 1990.

RECEBIDO EM: 20/08/2019

ENVIADO EM: 29/06/2020 